\title{
Celebrating paediatric dentistry's history of scientific publishing
}

The September issue of the International Journal of Paediatric Dentistry - which has been published online (https://onlinelibrary. wiley.com/toc/1365263x/current) - marks two anniversaries, 30 years since its inaugural issue in 1991 and 50 years since the specialty published its first scientific journal, Proceedings of the British Paedodontic Society (PBPS).

The modest $P B P S$ went on to become the Journal of Paediatric Dentistry until in 1991, as result of a merger with the publication of the International Association of Paediatric Dentistry, it became the prestigious International Journal of Paediatric Dentistry (IJPD). Since then, the IJPD has been published bi-monthly as the official journal of both organisations.

Dr Chris Vernazza, the BSPD's Honorary Editor (pictured), has marked the double anniversary with an editorial in the September issue in which he reflects on the dental topics which are of continuing universal concern as well as shifting priorities in response to innovation and scientific progress.

For instance, changes in clinical management as a result of the bonding revolution of the 1960s and 1970s are apparent from the change in content of the journal between 1971 and 1991. In the former, two pages of advertising are dedicated to the promotion of Nuva Seal, an early fissure sealant. Advertisements for temporary crowns suggest that covering a diseased tooth with a crown has been a solution for paediatric dentists for more than half a century, although 50 years ago, a metal crown might have been placed on a fractured incisor!

Comparing 1971 with 1991 and 2021, Dr Vernazza says: 'There is now much more academic interest in the impact of oral health and disease on children and their families and how to address these in the broadest sense'.

He adds that whilst the science presented in the earlier editions is robust and well reported, today's academic paediatric dentists may collaborate with a broader range of methodologists on studies which are, for example, more computational: 'We have a better toolbox of methods which we can apply to answer more questions'.

Dr Vernazza says: 'It was pioneering thinking by IAPD and BSPD leaders at the time, foremost Prof Gerry Winter, a UK dentist and secretary of IAPD, who saw that a merger would create a strong international presence and their foresight has proved correct'.

The BSPD is fortunate to have several members who were featured in the PBPS;

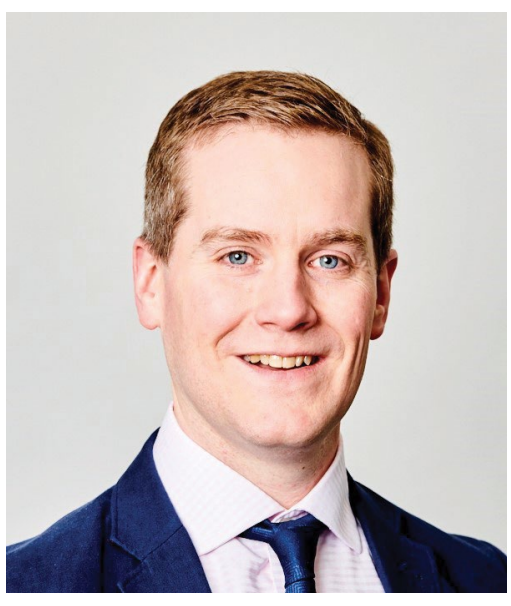

among them, Emeritus Professor Andrew Rugg-Gunn, whose study ('A comparison of the radiographical and clinical appearances of approximal carious lesions', $\mathrm{Proc} \mathrm{Br}$ Paedod Soc 1971; 1: 14-15) was the first of its kind in the UK and still referenced today. He, Professor John Murray and dental historian Stanley Gelbier all speak of the pride they felt in being published in the first edition.

The first editor of the IJPD was Professor Reg Andlaw - he was also the editor of PBPS - who wrote in the inaugural editorial: 'Our aim is to produce a journal that will quickly establish a high international reputation'.

Dr Vernazza concludes his editorial in the anniversary issue by saying: 'I think we can safely surmise that 30 years later, the journal has achieved these aims and we look forward to IJPD continuing to grow in quality and relevance over the next 30 years, 50 years and beyond'.

\section{LDCs pull out all the stops through pandemic}

The Local Dental Committees (LDCs) were praised for their significant support of the BDA Benevolent Fund at their latest AGM, which took place online on 2 September 2021.

As for many charities, it has been a particularly challenging year for the BDA Benevolent Fund. Fundraising opportunities fell away during the pandemic and there was a surge in applications from dental students, dentists and their families, as the profession felt the cruel effects of the COVID-19 pandemic.

As expenditure on grant giving soared by $15 \%$, there was a $25 \%$ fall in investment income, giving a troubling economic picture. However, LDCs recognised and truly stepped up, increasing their donations by almost $70 \%$.

Dr Austin Banner, Vice-Chairman, opened the presentation of the Annual Report and Accounts to the end of December 2020, by thanking the LDCs, seconded by Dr Chris Hayward, Treasurer. Austin went on to thank Ros Keeton, Laura Hannon and Susan Dare, for their remarkable resilience through the pandemic, and the swift and seamless handling of a move to working from home.

He then went on to outline the extension of services that had taken place, including a focus on health and wellbeing and financial education webinars. He noted the surge in financial support applications as a result of the pandemic and the growing trend that applicants are much younger than previously. The average age is now 31 years.

Other developments were highlighted, including a student research project, Advisory Council activity, marketing strategy development and a new website launch.

The usual AGM business was attended to, including the re-election of Dr Bill Creedon, for a further three years on the Board. Thanks were also given to $\mathrm{Dr}$ Julie Kirkby for 13 years of service and dedication as she stepped down and was wished a happy retirement. 